CLINICAL STUDY

\title{
TSH and free triiodothyronine concentrations are associated with weight loss in a lifestyle intervention and weight regain afterwards in obese children
}

\author{
Barbara Wolters, Nina Lass and Thomas Reinehr \\ Department of Pediatric Endocrinology, Diabetes and Nutrition Medicine, Vestische Hospital for Children and Children Datteln, University of \\ Witten/Herdecke, Dr F Steiner Street 5, D-45711 Datteln, Germany \\ (Correspondence should be addressed to T Reinehr; Email: t.reinehr@kinderklinik-datteln.de)
}

\begin{abstract}
Objective: The impact of thyroid hormones on weight loss in lifestyle interventions and on weight regain afterwards is unknown. Therefore, we studied the relationships between TSH, free triiodothyronine $\left(\mathrm{fT}_{3}\right)$, free thyroxine $\left(\mathrm{fT}_{4}\right)$, and weight status, as well as their changes during and after a lifestyle intervention in obese children.

Materials and methods: We evaluated the weight status as BMI-SDS in 477 obese children (mean age $10.6 \pm 2.7$ years, $46 \%$ male, mean BMI $28.1 \pm 4.5 \mathrm{~kg} / \mathrm{m}^{2}$ ) participating in a 1-year lifestyle intervention in a 2-year longitudinal study. Changes in BMI-SDS at 1 and 2 years were correlated with TSH, $\mathrm{fT}_{3}$, and $\mathrm{fT}_{4}$ concentrations at baseline and their changes during the intervention.

Results: A decrease in BMI-SDS during the intervention period $(-0.32 \pm 0.38 ; P<0.001)$ was significantly positively associated with baseline TSH and $\mathrm{fT}_{3}$ in multiple linear regression analyses adjusted for age, sex, pubertal stage, and baseline BMI-SDS. An increase in BMI-SDS after the end of the intervention $(+0.05 \pm 0.36 ; P=0.011)$ was significantly related to the decreases in $\mathrm{TSH}_{\text {and }} \mathrm{fT}_{3}$ during the intervention in multiple linear regression analyses adjusted for change in BMI-SDS during the intervention. In contrast to children with weight maintenance, children with weight regain after the end of the intervention demonstrated a decrease in their TSH levels $(-0.1 \pm 1.6$ vs $+0.2 \pm$ $1.6 \mathrm{mU} / \mathrm{l} ; P=0.03)$ and $\mathrm{fT}_{3}(-0.2 \pm 1.1 \mathrm{vs}+0.3 \pm 1.6 \mathrm{pg} / \mathrm{ml} ; P<0.001)$ during the intervention. Conclusions: The decreases in $\mathrm{TSH}$ and $\mathrm{fT}_{3}$ concentrations during the lifestyle intervention were associated with weight regain after the intervention. Future studies should confirm that the decreases in $\mathrm{TSH}$ and $\mathrm{fT}_{3}$ levels associated with weight loss are related to the change in metabolism such as resting energy expenditure.
\end{abstract}

European Journal of Endocrinology 168 323-329

\section{Introduction}

A moderate elevation of TSH concentrations, which is associated with triiodothyronine $\left(\mathrm{T}_{3}\right)$ values in or slightly above the upper normal range, is frequently found in obese humans $(1,2,3,4,5,6,7,8,9)$. These changes are reversible in weight loss independent of whether weight loss is obtained through diet or bariatric surgery $(2,7,8,10,11,12)$. Furthermore, a positive correlation between weight gain during 5 years and a progressive increase in serum TSH has also been reported (13). These findings suggest that the increase in TSH and $\mathrm{T}_{3}$ concentrations in obese subjects seems to be a consequence rather than a cause of obesity $(1,8,10)$.

The underlying mechanisms of the increases in TSH and free $\mathrm{T}_{3}\left(\mathrm{fT}_{3}\right)$ levels in obesity are largely unknown $(1,14)$. For example, a derangement in the hypothalamic-pituitary axis, an impaired feedback due to a lowered number of $\mathrm{T}_{3}$ receptors in the hypothalamus (thyroid hormone resistance), and a decrease in peripheral deiodinase activity have been postulated (2). Furthermore, non-synonymous mutations in the TSHR gene have been reported as a cause of increased TSH levels in obesity, but these mutations are rare (15). Additionally, seronegative autoimmune thyroiditis has been suggested since thyroid hypoechogenicity at ultrasound has been reported and antithyroid antibodies are frequently negative in obese children with elevated TSH and $\mathrm{fT}_{3}$ levels $(2,15,16)$. However, cytological samples obtained in obese children with elevated TSH levels, hypoechogenicity in ultrasound, and negative for thyroid autoantibodies have been reported to be normal, and, thus, excluded an autoimmune disorder (16). A possible explanation for thyroid hypoechogenicity at ultrasound observed in obese children could be the existence of a low-grade inflammation, a known characteristic of obesity (2). However, the most favored hypothesis of increased TSH 
levels in obesity is an increased leptin-mediated production of pro-TRH $(1,2)$.

It has been suggested that this moderate increase in TSH and consequently $\mathrm{fT}_{3}$ levels in obesity is an adaptation process to increase resting energy expenditure (REE) $(1,2)$. It is well known that basal metabolic rate, total energy expenditure, and sleeping energy expenditure are positively correlated with the serum total or $\mathrm{fT}_{3}$ concentrations, while the underlying pathways are not fully understood $(1,2,8,10,12)$. As a consequence of the increased REE, the availability of accumulated energy for conversion into fat is diminished. Since weight loss is associated with a decrease in thyroid hormones $(1,3,4,7,8,10)$, the resulting decrease in REE may contribute toward difficulties in maintaining weight loss.

To support the hypothesis that a decrease in TSH and $\mathrm{T}_{3}$ concentrations during a lifestyle intervention is associated with weight regain afterwards, we analyzed the impact of TSH and thyroid hormones and their changes during weight loss on the outcome of a lifestyle intervention in nearly 500 obese children. We hypothesize that increased basal TSH and $\mathrm{T}_{3}$ levels are associated with greater weight loss in a lifestyle intervention since REE is increased in these children. Furthermore, we hypothesize that a decrease in TSH and $\mathrm{T}_{3}$ concentrations during a lifestyle intervention is associated with difficulties in maintaining weight loss after the end of the intervention.

\section{Materials and methods}

The Local Ethics Committee of the University of Witten/Herdecke approved this prospective study. Informed consent was obtained from all subjects and their parents. This study is registered at ClinicalTrials.gov (NCT00435734).

We examined 477 obese children (mean age $10.6 \pm$ 2.7 years, $46 \%$ male, mean BMI $28.1 \pm 4.5 \mathrm{~kg} / \mathrm{m}^{2}$ ) completing the lifestyle intervention 'Obeldicks'. Children with endocrine or metabolic disorders including goiter and autoimmune thyroiditis were excluded from the study. Furthermore, we excluded children with TSH levels $>10 \mathrm{mU} / \mathrm{l}$. Smokers and children taking any medication including oral contraceptives were also excluded. Weight status was determined at baseline, at the end of the 1 -year intervention, and 1 year later $(=2$ years after baseline). TSH, $\mathrm{T}_{3}$, and thyroxine $\left(\mathrm{T}_{4}\right)$ concentrations were examined at baseline and 1 year later ( = end of the intervention). Our study protocol does not include a blood measurement at follow-up to avoid lost-to-follow-up rate after the end of the intervention.

\section{Measurements}

Weight status was determined as BMI. Height was measured to the nearest centimeter. Weight was measured in underwear to the nearest $0.1 \mathrm{~kg}$ using a calibrated balance scale. The degree of overweight was quantified using Cole's least mean square method, which normalizes the BMI skewed distribution in childhood and expressed BMI as a BMI-SDS (17). Obesity was defined as BMI $>97$ th percentile according to the definition of the International Obesity Task Force (18) using population-specific reference data for German children (19).

Pubertal stage according to Marshall and Tanner was determined by well-trained physicians. Pubertal developmental stage was categorized into three groups based on breast and genital stages (prepubertal: boys with genital stage I, girls with breast stage I; early pubertal: boys with genital stages II and III, girls with breast stages II and III; late/postpubertal: boys with genital stage $>$ III, girls with breast stage $>$ III).

$\mathrm{TSH}, \mathrm{fT}_{3}$, and free $\mathrm{T}_{4}\left(\mathrm{fT}_{4}\right)$ concentrations were determined in the fasting status. $\mathrm{TSH}, \mathrm{fT}_{3}$, and $\mathrm{fT}_{4}$ were measured by high-specific, solid-phase technique chemiluminescence immunoassays (Immulite; DPC, Los Angeles, CA, USA). Intra- and interassay variations were $<10 \%$. The normal values range between 0.2 and $3.0 \mathrm{mIU} / \mathrm{l}$ for TSH, between 3.0 and $5.4 \mathrm{pg} / \mathrm{ml}$ for $\mathrm{fT}_{3}$, and between 0.9 and $2.3 \mathrm{ng} / \mathrm{dl}$ for $\mathrm{fT}_{4}$.

In all children with TSH levels $>3 \mathrm{mU} / \mathrm{l}$, autoimmune thyroiditis was excluded by measuring antithyroidal peroxidase and thyroglobulin antibodies.

\section{Intervention}

The 1-year lifestyle intervention 'Obeldicks' has been described in detail elsewhere $(20,21)$. Briefly, this intervention is based on physical exercise, nutrition education, and behavior therapy including the individual psychological care of the child and its family. Exercise therapy consists of sports, instructions in physical exercise as part of all-day life, and in the reduction of the amount of time spent watching television. The nutritional course is based on the prevention concept of the 'Optimized mixed diet' which is both fat and sugar reduced containing 30\% energy intake (E) of fat, $15 \mathrm{E} \%$ proteins, and $55 \mathrm{E} \%$ carbohydrates including $5 \mathrm{E} \%$ sugar.

\section{Statistical analysis}

Statistical analysis was performed using WinSTAT for Excel. All variables were normally distributed as tested by the Kolmogorov-Smirnov test. Correlations were calculated by Pearson's correlation. Multiple linear regression analyses were calculated with a reduction in BMI-SDS during the intervention or with a change in BMI-SDS between the end of the intervention and 1 year later as dependent variables, and age, sex, pubertal stage, baseline BMI-SDS, and TSH, fT 3 , and $\mathrm{fT}_{4}$ respectively as independent variables. Sex was used as a classified variable. T-tests for paired observations were 
used to compare the variables. The changes in TSH and thyroid hormones were analyzed separately for children with and without a reduction of $>0.5 \mathrm{BMI}-$ SDS in the lifestyle intervention since this amount of overweight reduction was associated with an improvement in cardiovascular risk factors $(22,23)$. Furthermore, children were divided into children with weight regain defined by an increase in BMI-SDS after the end of the intervention and children with weight maintenance defined by stable or decreasing BMI-SDS after the end of the intervention. Corrections for multiple testing were performed by Bonferroni's adjustment. A $P<0.05$ was considered as statistically significant. Data are presented as means and s.D.s.

\section{Results}

At baseline, $39 \%$ of the children demonstrated TSH levels above $3.0 \mathrm{mIU} / \mathrm{l}$ for $\mathrm{TSH}, 5.1 \%$ of the subjects showed $\mathrm{fT}_{3}$ concentrations $>5.4 \mathrm{pg} / \mathrm{ml}$, while only $1.2 \%$ had $\mathrm{fT}_{4}$ levels $>2.3 \mathrm{ng} / \mathrm{dl}$ (see also Table 1 ). None of the children with TSH levels $>3 \mathrm{mU} / \mathrm{l}$ had $\mathrm{fT}_{3}$ or $\mathrm{fT}_{4}$ levels below the normal range. A total of 20 children $(11 \%)$ with $\mathrm{TSH}$ levels $>3 \mathrm{mU} / \mathrm{l}$ had $\mathrm{fT}_{3}>5.4 \mathrm{pg} / \mathrm{ml}$ and one child $(0.5 \%)$ with TSH levels $>3 \mathrm{mU} / \mathrm{l}$ had $\mathrm{fT}_{4}$ levels $>2.3 \mathrm{ng} / \mathrm{dl}$. A total of 20 children $(83 \%)$ with $\mathrm{fT}_{3}$ $>5.4 \mathrm{pg} / \mathrm{ml}$ showed TSH levels $>3 \mathrm{mU} / \mathrm{l}$ and one child (17\%) with $\mathrm{fT}_{4}$ levels $>2.3 \mathrm{ng} / \mathrm{dl}$ demonstrated $\mathrm{TSH}$ levels $>3 \mathrm{mU} / \mathrm{l}$.

The changes in weight status during the 1-year intervention period and in the course of 1 year after the end of the intervention are demonstrated in Table 1. Children had a significant reduction in their BMI-SDS in the intervention period $(-0.32 \pm 0.38 ; P<0.001)$. After the end of the intervention, BMI-SDS increased significantly $(+0.05 \pm 0.36 ; P=0.011)$. The BMI-SDS 2 years after baseline was significantly lower compared with baseline $(-0.27 \pm 0.49 ; P<0.001)$. The changes in BMI-SDS during the intervention period were significantly negatively associated with the changes in BMI-SDS between the end of the intervention and 1 year later $(r=-0.14 ; P<0.001)$, which means that children with a higher degree of weight loss tend to increase their BMI-SDS after the end of the intervention.
In the entire study population, TSH and thyroid hormones did not change significantly during the lifestyle intervention (see Table 1). The 119 children with a decrease in BMI-SDS >0.5 in the intervention period (baseline BMI-SDS, 2.48 \pm 0.39 ; change in BMI-SDS during the intervention, $-0.78 \pm 0.27$ ) demonstrated a significant decrease in their $\mathrm{TSH}(-0.4 \pm 1.7 \mathrm{mU} / \mathrm{l} ; \quad P=0.014)$ and $\mathrm{fT}_{3}(-0.3$ $\pm 1.4 \mathrm{pg} / \mathrm{ml} ; P=0.018)$ concentrations, while $\mathrm{fT}_{4}$ levels remained stable $(P=0.507)$. Children with a decrease in BMI-SDS $<0.5$ in the intervention period (baseline BMI-SDS, 2.49 \pm 0.40 ; change in BMI-SDS during the intervention, $-0.15 \pm 0.22)$ showed no significant changes in their TSH and thyroid hormone concentrations during the intervention period.

The 119 children with a reduction in BMI-SDS $>0.5$ in the intervention period demonstrated significantly higher $\mathrm{TSH}$ and $\mathrm{fT}_{3}$ concentrations at baseline when compared with the 358 children without a BMI-SDS reduction $>0.5$, while $\mathrm{fT}_{4}$ levels did not differ significantly between these groups (see Fig. 1).

The changes in BMI-SDS in the intervention period were significantly associated with baseline TSH $(r=0.21 ; P<0.001)$ and $\mathrm{fT}_{3}(r=0.22 ; P<0.001)$, but not with $\mathrm{fT}_{4}(r=0.05 ; P=0.151)$. The associations between TSH and thyroid hormones at baseline and changes in weight status during the intervention in multiple linear regression analyses adjusted for age, sex, pubertal status, and baseline BMI-SDS are presented in Table 2. Higher baseline $\mathrm{TSH}$ and $\mathrm{fT}_{3}$ concentrations were significantly related to a greater BMI-SDS reduction in the intervention period.

The changes in BMI-SDS during the intervention period were significantly related to the changes in TSH $(r=0.21 ; P<0.001)$ and $\mathrm{fT}_{3}(r=0.22 ; P<0.001)$, but not to the changes in $\mathrm{fT}_{4}(P=0.150)$.

Children with weight regain after the end of the intervention demonstrated a decrease in TSH and $\mathrm{fT}_{3}$ concentrations during the lifestyle intervention in contrast to children with weight maintenance after the end of the intervention, while $\mathrm{fT}_{4}$ levels did not differ significantly between these groups (see Fig. 2).

The changes in TSH and thyroid hormone concentrations during the intervention period were significantly negatively related to the changes in BMI-SDS

Table 1 Changes in weight status (as BMI-SDS) and TSH, $\mathrm{fT}_{3}$, and $\mathrm{fT}_{4}$ concentrations in 477 obese children participating in the 1-year lifestyle intervention 'Obeldicks' in the course of 2 years. Data are presented as mean and S.D. Values that are significant after multiple testing corrections are highlighted in bold.

\begin{tabular}{lcccccc}
\hline & Baseline & 1 year & 2 years & $\begin{array}{c}\boldsymbol{P} \text { value (BL compared } \\
\text { with 1 year) }\end{array}$ & $\begin{array}{c}\boldsymbol{P} \text { value (BL compared } \\
\text { with 2 years) }\end{array}$ & $\begin{array}{c}\boldsymbol{P} \text { value (1 year } \\
\text { compared with 2 years) }\end{array}$ \\
\hline $\mathrm{BMl}-\mathrm{SDS}$ & $\mathbf{2 . 4 9} \pm \mathbf{0 . 4 0}$ & $\mathbf{2 . 1 7} \pm \mathbf{0 . 5 3}$ & $\mathbf{2 . 2 2} \pm \mathbf{0 . 5 9}$ & $<\mathbf{0 . 0 0 1}$ & $<\mathbf{0 . 0 0 1}$ & 0.011 \\
$\mathrm{TSH}(\mathrm{mU} / \mathrm{l})$ & $3.0 \pm 1.4$ & $3.0 \pm 1.5$ & ND & 0.947 & - & - \\
$\mathrm{fT}_{3}(\mathrm{pg} / \mathrm{ml})$ & $4.2 \pm 0.8$ & $4.3 \pm 1.1$ & $\mathrm{ND}$ & 0.630 & - & - \\
$\mathrm{fT}_{4}(\mathrm{ng} / \mathrm{dl})$ & $1.2 \pm 0.3$ & $1.2 \pm 0.4$ & $\mathrm{ND}$ & 0.563 & - & -
\end{tabular}

ND, not determined; BL, baseline. 

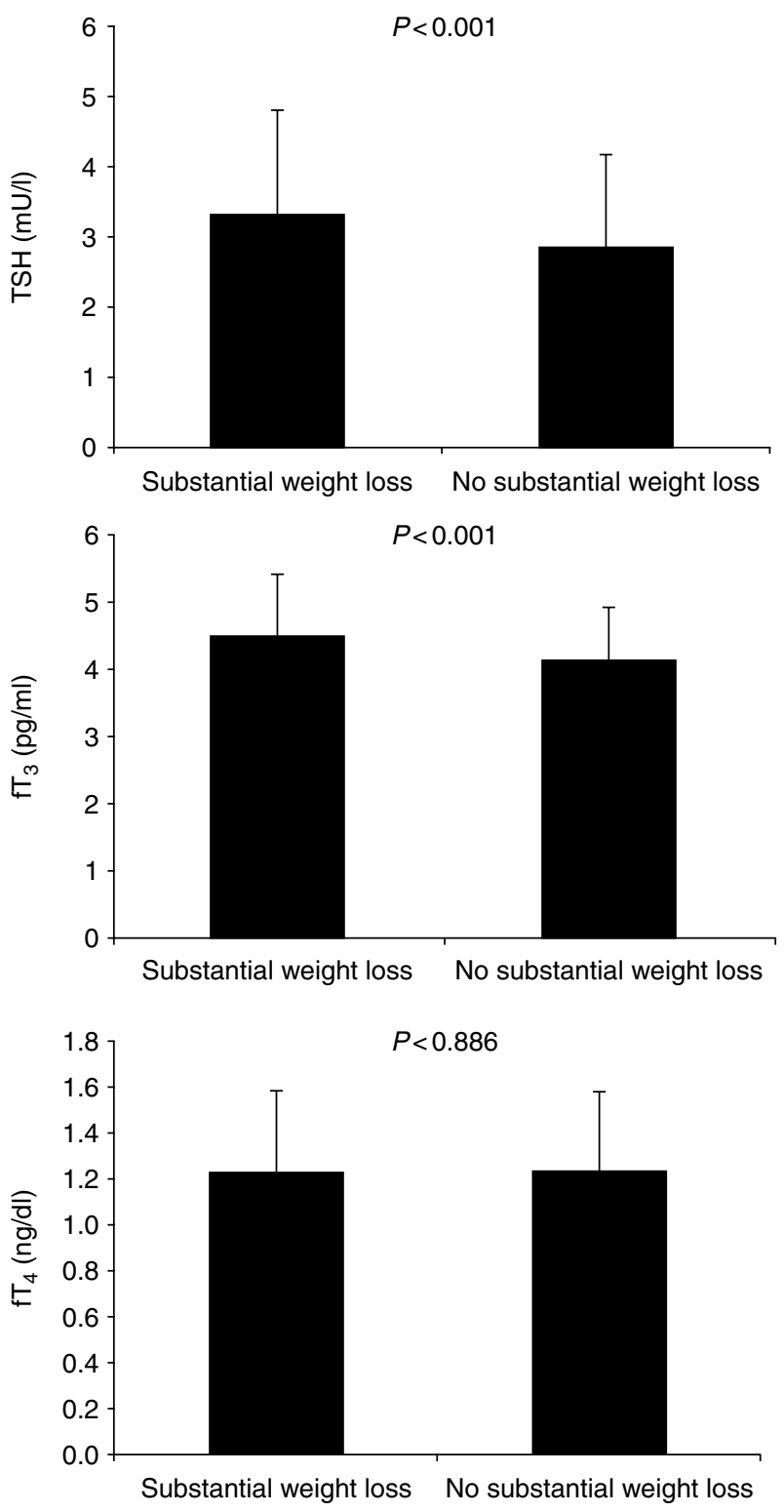

Figure 1 Baseline $\mathrm{TSH}, \mathrm{fT}_{3}$, and $\mathrm{fT}_{4}$ levels in the 477 obese children subjected to weight loss in the lifestyle intervention (data as mean and S.D., substantial weight loss defined by BMI-SDS reduction $>0.5$ ).

after the end of the intervention (TSH, $r=-0.11$; $P=0.010 ; \mathrm{fT}_{3}, r=-0.16 ; P<0.001 ; \mathrm{fT}_{4}, r=-0.06$; $P=0.101)$. The associations between the changes in TSH and thyroid hormone levels in the intervention period and the changes in weight status after the end of the intervention in multiple linear regression analyses adjusted for age, sex, pubertal status, and the changes in BMI-SDS during the intervention are presented in Table 3. A greater decrease in $\mathrm{TSH}$ and $\mathrm{fT}_{3}$ levels during the intervention was significantly related to a greater increase in BMI-SDS after the end of the intervention.

\section{Discussion}

This is the first longitudinal study in obese children analyzing the associations between TSH and thyroid hormones and weight status respective weight regain during and after a lifestyle intervention. In accordance with previous studies, obese children in our study demonstrated frequently slightly elevated TSH and $\mathrm{fT}_{3}$ levels at baseline, while substantial weight loss (decrease in BMI-SDS >0.5) was associated with a normalization of $\mathrm{TSH}$ and $\mathrm{fT}_{3}(1,2,3,4,5,6,7,8,9$, $10,11,15,24)$. We demonstrated that the BMI-SDS reduction during the lifestyle intervention was associated with a reduction in TSH and $\mathrm{fT}_{3}$ concentrations according to a study in adults reporting a positive correlation between weight gain during 5 years and a progressive increase in serum TSH (13). Most importantly, baseline $\mathrm{TSH}$ and $\mathrm{fT}_{3}$ levels were positively related to BMI-SDS reduction in the lifestyle intervention period and a decrease in $\mathrm{TSH}$ and $\mathrm{fT}_{3}$ levels during this intervention was associated with an increase in BMI-SDS after the end of the intervention in our study.

These findings suggest that $\mathrm{TSH}$ and $\mathrm{fT}_{3}$ concentrations and their changes predict in part weight changes during and after a lifestyle intervention. This relationship may be explained by the impact of thyroid hormones on REE. Increased thyroid hormones as in childhood obesity are associated with increased REE. Thyroid hormones, especially $\mathrm{T}_{3}$, regulate both the resting metabolic rate and thermogenesis and lead to lipolysis $(25,26,27,28)$. An increase in energy expenditure reduces the availability of energy for conversion into fat. When TSH and $\mathrm{fT}_{3}$ concentrations decrease in a parallel manner to a reduction of overweight as demonstrated in many studies $(1,3,4$, $7,8,10)$, then we can also expect a reduction in energy expenditure. Indeed, a decrease in energy expenditure due to weight loss has been shown in several studies in children and adults $(1,29,30,31)$ and may represent one of the causes of the difficulties in maintaining weight loss. It has been reported that a decrease of

Table 2 Associations between $\mathrm{TSH}_{1} \mathrm{fT}_{3}$, and $\mathrm{fT}_{4}$ levels at baseline and weight changes during a 1-year lifestyle intervention in the 477 obese children. The b-estimators were derived from linear regression models (adjustment for age (linear), sex, pubertal stage, and baseline BMI-SDS). Values that are significant after multiple testing corrections are highlighted in bold. Positive values of the effect size for the changes $(\Delta)$ indicate a reduction in BMI-SDS.

\begin{tabular}{|c|c|c|c|}
\hline & TSH $(\mathrm{mU} / \mathrm{l})$ & $\begin{array}{c}\mathbf{f T}_{\mathbf{3}} \\
(\mathrm{pg} / \mathrm{ml})\end{array}$ & $\mathrm{fT}_{4}(\mathrm{ng} / \mathrm{dl})$ \\
\hline $\begin{array}{l}\Delta \mathrm{BMI}-\mathrm{SDS} \text { b-estimator } \\
95 \% \mathrm{Cl} \\
P_{\text {value }} \\
\mathrm{r}^{2}\end{array}$ & $\begin{array}{l}0.05 \\
0.03,0.07 \\
1.18 \times 10^{-5} \\
0.13\end{array}$ & $\begin{array}{l}0.06 \\
0.02,0.06 \\
0.002 \\
0.11\end{array}$ & $\begin{array}{l}0.01 \\
-0.09,0.11 \\
0.795 \\
0.08\end{array}$ \\
\hline
\end{tabular}

For each thyroid hormone effect size (b-estimators), their $95 \%$ confidence interval $(95 \% \mathrm{Cl})$, the $P$ values, and the $r^{2}$ are listed. 

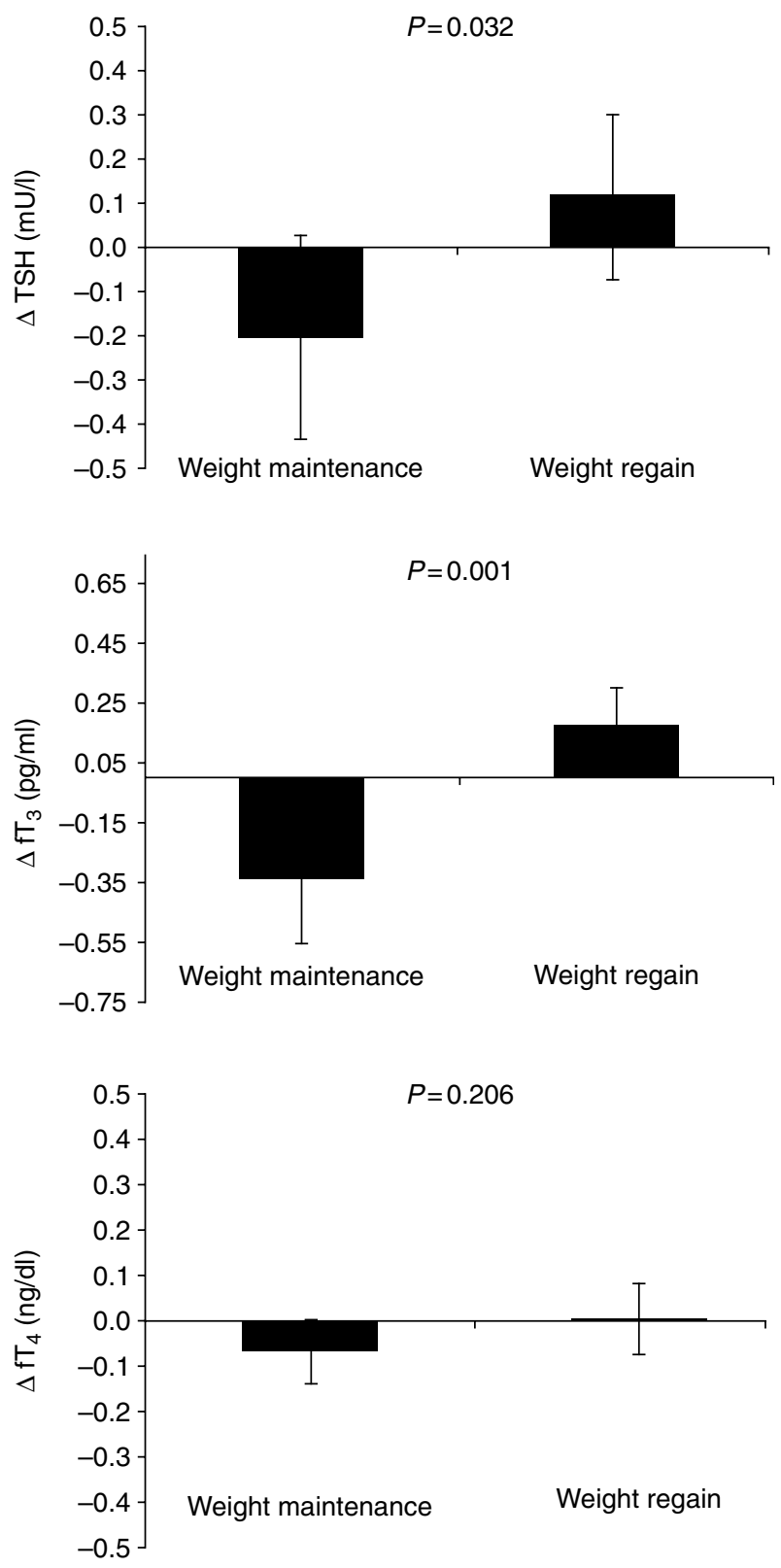

Figure 2 Changes in $\mathrm{TSH}, \mathrm{fT}_{3}$, and $\mathrm{fT}_{4}$ levels during the lifestyle intervention in the 477 obese children subjected to weight regain after the lifestyle intervention in the course of 1 year (data as mean and $95 \%$ confidence interval, weight regain defined by BMI-SDS increase, and weight maintenance defined by stable or decreasing BMI-SDS).

$1 \mathrm{IU} / \mathrm{l}$ of serum TSH concentrations, within normal range limits, is accompanied by a reduction in energy expenditure of $75 \pm 150 \mathrm{kcal} /$ day. This reduction corresponds to $8 \pm 17 \mathrm{~g}$ stored fat, equivalent to several kilograms over a period of years (32).

Since i) the decrease in BMI-SDS in the lifestyle intervention was associated with the decrease in TSH and ii) $\mathrm{fT}_{3}$ levels and the BMI-SDS reduction during the lifestyle intervention were a predictor of weight regain after the end of the intervention, one might speculate whether weight regain after the lifestyle intervention is caused by greater weight loss and not by the decrease in $\mathrm{TSH}$ and $\mathrm{fT}_{3}$ levels. However, even after adjustment for changes in BMI-SDS in the intervention period in multiple linear regression analyses, the decrease in TSH and $\mathrm{fT}_{3}$ concentrations during the intervention was related to weight regain after the end of the intervention.

We need to keep in mind that the explained variances of BMI-SDS change during the intervention and of BMI-SDS increase after the end of the intervention by thyroid changes were only low to moderate in multiple linear regression analyses, suggesting that other factors such as eating and exercise behavior, social or genetic background might be more important for the outcome of a lifestyle intervention. However, the significant relationships between $\mathrm{TSH}$ and $\mathrm{fT}_{3}$ concentrations and their changes and the changes in BMI-SDS during and after a lifestyle intervention are an important finding: no success in a lifestyle intervention and weight regain is not only caused by the behavior of obese children but also by their metabolism. Therefore, it is not adequate to blame unsuccessful participants of lifestyle interventions.

Interestingly, $\mathrm{fT}_{4}$ levels or their changes were not related to the changes in BMI-SDS during or after the end of the intervention in contrast to $\mathrm{fT}_{3}$ and TSH levels. Furthermore, $\mathrm{fT}_{4}$ levels did not decrease in substantial weight loss in contrast to TSH and $\mathrm{fT}_{3}$ levels. These findings suggest an increase in reverse $\mathrm{T}_{3}\left(\mathrm{rT}_{3}\right)$ in weight loss. It has been reported that $\mathrm{fT}_{3}$ levels are increased in obesity also due to changes in the monodeiodination pathway (1). Approximately $80 \%$ of the circulating $\mathrm{T}_{3}$ is derived by extrathyroidal monodeiodination of $\mathrm{T}_{4}$, whereas $\mathrm{rT}_{3}$ is almost completely produced by extrathyroidal $\mathrm{T}_{4}$ monodeiodination. In normal-weight humans, monodeiodination of $\mathrm{T}_{4}$ produces approximately equal amounts of $\mathrm{T}_{3}$ and $\mathrm{rT}_{3}$. However, in obesity, production of $\mathrm{rT}_{3}$ is decreased, while production of $\mathrm{T}_{3}$ is increased (1).

Table 3 Associations between the changes in $\mathrm{TSH}, \mathrm{fT}_{3}$, and $\mathrm{fT}_{4}$ concentrations during the intervention and weight regain after the end of the lifestyle intervention in the 477 obese children. The b-estimators were derived from linear regression models (adjustment for age (linear), sex, pubertal stage, and change in BMI-SDS during the intervention). Values that are significant after multiple testing corrections are highlighted in bold. Negative values of the effect size for the changes $(\Delta)$ indicate a weight regain (=increase in BMI-SDS after the end of the intervention).

\begin{tabular}{llll}
\hline & $\Delta \mathrm{TSH}(\mathrm{mU} / \mathrm{l})$ & $\Delta \mathrm{fT}_{\mathbf{3}}(\mathrm{pg} / \mathrm{ml})$ & $\Delta \mathbf{f T}_{\mathbf{4}}(\mathrm{ng} / \mathrm{dl})$ \\
\hline$\Delta$ BMI-SDS b-estimator & $-\mathbf{0 . 0 2}$ & $-\mathbf{0 . 0 4}$ & -0.04 \\
$95 \% \mathrm{Cl}$ & $-\mathbf{0 . 0 3},-\mathbf{0 . 0 1}$ & $-\mathbf{0 . 0 6},-\mathbf{0 . 0 2}$ & $-0.09,0.01$ \\
$P$ value & $\mathbf{0 . 0 0 9}$ & $\mathbf{0 . 0 0 3}$ & 0.176 \\
$r^{2}$ & $\mathbf{0 . 0 4}$ & $\mathbf{0 . 0 5}$ & 0.03
\end{tabular}

For each thyroid hormone effect size (b-estimators), their $95 \%$ confidence interval $(95 \% \mathrm{Cl})$, the $P$ values, and the $r^{2}$ are listed. 
Since other mechanisms than obesity per se are discussed to be the underlying mechanisms of the increase in TSH and thyroid hormone levels, we need to consider that the relationships between TSH, $\mathrm{fT}_{3}$, and weight change may represent an epiphenomenon caused by a third factor. For example, if inflammation is the driver of changes in TSH and thyroid hormone levels in obesity as discussed (2), then a change in weight status is likely to be associated with a change in the grade of inflammation and may explain the relationships between the change in weight status and TSH respective thyroid hormones.

The strengths of this study are the longitudinal design including not only the intervention period but also a follow-up period after the end of the intervention as well as the large study sample. However, this study has a few potential limitations. First, BMI percentiles were used to classify overweight. Although BMI is a good measure for overweight, one needs to be aware of its limitations as an indirect measurement of adiposity. Measurement of body composition would be ideal. However, the gold standards such as dual-energy X-ray absorptiometer or indirect calorimetry are very difficult to perform in a large collection of obese children. We evaluated changes in BMI in relation to TSH and thyroid hormones, whereas it might have been more appropriate to evaluate, or at least include, measurements of lean body mass. Lean body mass appears to be a major determinant of thyroxin requirement (33). Furthermore, we did not measure REE, which is very laborious in a large collection of children. Second, we did not perform ultrasound measurement to exclude seronegative autoimmune thyroiditis. However, a recent study has excluded autoimmune disorders by cytological samples obtained in obese children with elevated TSH levels and hypoechogenicity in ultrasound (16). Finally, we did not differentiate the effect of diet, increased physical exercise, and weight loss on TSH and thyroid hormones and weight regain due to our study protocol. In contrast to exercise-induced weight loss, diet-induced weight loss has been reported to be associated with changes in thyroid hormone production (34).

In summary, we found moderately increased TSH and $\mathrm{fT}_{3}$ concentrations in obese children, which normalized in substantial weight loss. Since both baseline TSH and $\mathrm{fT}_{3}$ levels as well as the decrease in these hormones during weight loss were associated with changes in BMI-SDS, we put forward the hypothesis that increased TSH and $\mathrm{T}_{3}$ concentrations may represent an adaptation process of obesity, increasing the REE to reduce the availability of energy for conversion to fat. Future studies should confirm that the decrease in TSH and $\mathrm{T}_{3}$ during a successful lifestyle intervention is associated with a decrease in REE, representing a negative predictive factor for weight maintenance after the lifestyle intervention.

\section{Declaration of interest}

The authors declare that there is no conflict of interest that could be perceived as prejudicing the impartiality of the research reported.

\section{Funding}

$\mathrm{T}$ Reinehr and B Wolters received grant support from the 'Kompetenznetz Adipositas (Competence Network for Adiposity)' funded by the German Federal Ministry of Education and Research (FKZ: 01GI1120A). The hypothesis development, analysis, interpretation, and conclusions contained in this study are those of the authors alone.

\section{Author contribution statement}

$\mathrm{T}$ Reinehr developed the study design and wrote the first draft of the paper and performed the statistical analyses. N Lass and B Wolters performed the anthropometrical measurements. All authors discussed the findings.

\section{Acknowledgements}

We thank the children who participated in this study.

\section{References}

1 Reinehr T. Obesity and thyroid function. Molecular and Cellular Endocrinology 2010316 165-171. (doi:10.1016/j.mce.2009. 06.005)

2 Reinehr T. Thyroid function in the nutritionally obese child and adolescent. Current Opinion in Pediatrics 201123 415-420. (doi:10.1097/MOP.0b013e328344c393)

3 Shalitin S, Yackobovitch-Gavan M \& Phillip M. Prevalence of thyroid dysfunction in obese children and adolescents before and after weight reduction and its relation to other metabolic parameters. Hormone Research 200971 155-161. (doi:10.1159/ 000197872)

4 Marras V, Casini MR, Pilia S, Carta D, Civolani P, Porcu M, Uccheddu AP \& Loche S. Thyroid function in obese children and adolescents. Hormone Research in Paediatrics 201073 193-197. (doi:10.1159/000284361)

5 Dekelbab BH, Abou Ouf HA \& Jain I. Prevalence of elevated thyroid-stimulating hormone levels in obese children and adolescents. Endocrine Practice 201016 187-190. (doi:10.4158/ EP09176.OR)

6 Grandone A, Santoro N, Coppola F, Calabro P, Perrone L \& Del Giudice EM. Thyroid function derangement and childhood obesity: an Italian experience. BMC Endocrine Disorders 2010108. (doi:10.1186/1472-6823-10-8)

7 Reinehr T, de Sousa G \& Andler W. Hyperthyrotropinemia in obese children is reversible after weight loss and is not related to lipids. Journal of Clinical Endocrinology and Metabolism 200691 3088-3091. (doi:10.1210/jc.2006-0095)

8 Reinehr T, Isa A, de Sousa G, Dieffenbach R \& Andler W. Thyroid hormones and their relation to weight status. Hormone Research 200870 51-57. (doi:10.1159/000129678)

9 Rotondi M, Leporati P, La Manna A, Pirali B, Mondello T, Fonte R, Magri F \& Chiovato L. Raised serum TSH levels in patients with morbid obesity: is it enough to diagnose subclinical hypothyroidism? European Journal of Endocrinology $2009 \mathbf{1 6 0} 403-408$. (doi:10.1530/EJE-08-0734)

10 Reinehr T \& Andler W. Thyroid hormones before and after weight loss in obesity. Archives of Disease in Childhood 200287 320-323. (doi:10.1136/adc.87.4.320) 
11 Sari R, Balci MK, Altunbas H \& Karayalcin U. The effect of body weight and weight loss on thyroid volume and function in obese women. Clinical Endocrinology 200359 258-262. (doi:10.1046/j. 1365-2265.2003.01836.x)

12 Rotondi M, Magri F \& Chiovato L. Thyroid and obesity: not a oneway interaction. Journal of Clinical Endocrinology and Metabolism 201196 344-346. (doi:10.1210/jc.2010-2515)

13 Knudsen N, Laurberg P, Rasmussen LB, Bülow I, Perrild H, Ovesen L \& Jørgensen T. Small differences in thyroid function may be important for body mass index and the occurrence of obesity in the population. Journal of Clinical Endocrinology and Metabolism 200590 4019-4024. (doi:10.1210/jc.2004-2225)

14 Legradi G, Emerson CH, Ahima RS, Flier JS \& Lechan RM. Leptin prevents fasting-induced suppression of prothyrotropin-releasing hormone messenger ribonucleic acid in neurons of the hypothalamic paraventricular nucleus. Endocrinology $1997 \mathbf{1 3 8}$ 2569-2576. (doi:10.1210/en.138.6.2569)

15 Rapa A, Monzani A, Moia S, Vivenza D, Bellone S, Petri A, Teofoli F, Cassio A, Cesaretti G, Corrias A et al. Subclinical hypothyroidism in children and adolescents: a wide range of clinical, biochemical, and genetic factors involved. Journal of Clinical Endocrinology and Metabolism 200994 2414-2420. (doi:10.1210/jc.2009-0375)

16 Radetti G, Kleon W, Buzi F, Crivellaro C, Pappalardo L, di Iorgi N \& Maghnie M. Thyroid function and structure are affected in childhood obesity. Journal of Clinical Endocrinology and Metabolism 200893 4749-4754. (doi:10.1210/jc.2008-0823)

17 Cole TJ. The LMS method for constructing normalized growth standards. European Journal of Clinical Nutrition $1990 \mathbf{4 4} 45-60$.

18 Cole TJ, Bellizzi MC, Flegal KM \& Dietz WH. Establishing a standard definition for child overweight and obesity worldwide: international survey. BMJ 2000320 1240-1243. (doi:10.1136/bmj. 320.7244.1240)

19 Kromeyer-Hauschild K, Wabitsch M, Kunze D, Geller F, Geiß HC, Hesse V, von Hippel A, Jaeger U, Johnsen D, Korte $W$ et al. Percentiles of body mass index in children and adolescents evaluated from different regional German studies. Monatsschrift für Kinderheilkunde $2001 \quad 149$ 807-818. (doi:10.1007/s00 1120170107)

20 Reinehr T, Kersting M, Wollenhaupt A, Alexy U, Kling B, Ströbele $\mathrm{K} \&$ Andler $\mathrm{W}$. Evaluation of the training program "OBELDICKS" for obese children and adolescents. Klinische Padiatrie 2005217 1-8. (doi:10.1055/s-2004-816246)

21 Reinehr T, Temmesfeld M, Kersting M, de Sousa G \& Toschke AM. Four-year follow-up of children and adolescents participating in an obesity intervention program. International Journal of Obesity 200731 1074-1077. (doi:10.1038/sj.ijo.0803637)

22 Wunsch R, de Sousa G, Toschke AM \& Reinehr T. Intima-media thickness in obese children before and after weight loss. Pediatrics 2006118 2334-2340. (doi:10.1542/peds.2006-0302)
23 Reinehr T, Kiess W, Kapellen T \& Andler W. Insulin sensitivity among obese children and adolescents, according to degree of weight loss. Pediatrics 2004114 1569-1573. (doi:10.1542/peds. 2003-0649-F)

24 Pacifico L, Anania C, Ferraro F, Andreoli GM \& Chiesa C. Thyroid function in childhood obesity and metabolic comorbidity. Clinica Chimica Acta 2012413 396-405. (doi:10.1016/j.cca.2011.11. 013)

25 Blennemann B, Leahy P, Kim TS \& Freake HC. Tissue-specific regulation of lipogenic mRNAs by thyroid hormone. Molecular and Cellular Endocrinology 1995110 1-8. (doi:10.1016/03037207(95)03509-6)

26 Roti E, Minelli R \& Salvi M. Thyroid hormone metabolism in obesity. International Journal of Obesity and Related Metabolic Disorders 200024 (Suppl 2) S113-S115. (doi:10.1038/sj.ijo. 0801293)

27 Shin DJ \& Osborne TF. Thyroid hormone regulation and cholesterol metabolism are connected through sterol regulatory element-binding protein-2 (SREBP-2). Journal of Biological Chemistry 2003278 34114-34118. (doi:10.1074/jbc.M305417200)

28 Silva JE. The thermogenic effect of thyroid hormone and its clinical implications. Annals of Internal Medicine 2003139 205-213.

29 Kiortsis DN, Durack I \& Turpin G. Effects of a low-calorie diet on resting metabolic rate and serum tri-iodothyronine levels in obese children. European Journal of Pediatrics 1999158 446-450. (doi:10.1007/s004310051117)

30 Heshka S, Yang MU, Wang J, Burt P \& Pi-Sunyer FX. Weight loss and change in resting metabolic rate. American Journal of Clinical Nutrition $1990 \mathbf{5 2}$ 981-986.

31 Hill JO, Sparling PB, Shields TW \& Heller PA. Effects of exercise and food restriction on body composition and metabolic rate in obese women. American Journal of Clinical Nutrition 198746 622-630.

32 al-Adsani H, Hoffer LJ \& Silva JE. Resting energy expenditure is sensitive to small dose changes in patients on chronic thyroid hormone replacement. Journal of Clinical Endocrinology and Metabolism 199782 1118-1125. (doi:10.1210/jc.82.4.1118)

33 Santini F, Pinchera A, Marsili A, Ceccarini G, Castagna MG, Valeriano R, Giannetti M, Taddei D, Centoni R, Scartabelli G et al. Lean body mass is a major determinant of levothyroxine dosage in the treatment of thyroid diseases. Journal of Clinical Endocrinology and Metabolism 200590 124-127. (doi:10.1210/jc.2004-1306)

34 Katzeff HL \& Selgrad C. Maintenance of thyroid hormone production during exercise-induced weight loss. American Journal of Physiology 1991261 E382-E388.

Received 23 September 2012

Accepted 3 December 2012 